\title{
O centenário debate sobre a interpretação e os fundamentos da Física Quântica'
}

Olival Freire Junior*

\section{Resumo}

Apresentamos reflexões sobre a história da mecânica quântica, em especial do debate sobre os fundamentos e as interpretações desta teoria científica. Tais reflexões podem ser de utilidade no contexto dos preparativos para o projeto sobre o centenário da mecânica quântica, em 2025. Considerando-se a controvérsia sobre os fundamentos desta teoria como uma controvérsia também quase centenária, examinamos três aspectos: a atitude dos físicos em face da pesquisa em fundamentos da teoria quântica, a atitude dos filósofos da ciência em face da controvérsia e o papel dos experimentos na elucidação desta controvérsia. As lições que extraímos desta análise podem ser de utilidade no ensino da teoria quântica, particularmente nas primeiras etapas do contato dos estudantes com esta teoria científica.

Palavras-chave: história da Física Quântica; complementaridade; dissidentes quânticos.

\section{Introdução}

Estamos nos aproximando do centenário da mecânica quântica, tomando 2025 como o marco deste centenário, e existe, hoje, uma articulação internacional para marcar os 100 anos da mecânica quântica, o projeto Quantum Century. A Sociedade Brasileira de Física está nesse processo. Trata-se não só de comemorar o centenário da mecânica quântica, mas também de refletir sobre como, nesse século, a mecânica quântica alterou e reformatou a Física, a cultura da Física, a cultura da ciência, como uma das teorias científicas mais centrais.

Doutor em História Social pela Universidade de São Paulo. Professor Titular da Universidade Federal da Bahia e
Pesquisador CNPq na área de História da Ciência. Orcid: 0000-0003-3401-8885. E-mail: olival.freire@gmail.com

https://doi.org/10.5335/rbecm.v4i3.12911

http://creativecommons.org/licenses/by-nc-nd/4.0

ISSN: 2595-7376 
Aqui, há um jogo de palavras que o português não pega completamente, trata-se da expressão Quantum Century. Estamos procurando qual é a melhor expressão em português, mas o fato é que não é o centenário da mecânica quântica. É o século da mecânica quântica. Quando essas articulações tiveram início, a partir do pessoal da American Physics Society, eu mesmo disse numa das reuniões que, se fosse o centenário da mecânica quântica, seria uma festa dos alemães, porque mecânica quântica é um produto alemão. Seriamos convidados para a festa, e eles falariam algumas coisas. Mas, se é o século da mecânica quântica, aí, todo o mundo da Física, em todos os países em que a Física se desenvolveu desde então, tem o que falar. Quero correlacionar isso com a nossa temática. A mecânica quântica tem essa particularidade de que, nesses 100 anos, essa teoria reestruturou a disciplina da Física e é considerada a sua teoria mais fundamental. É uma teoria com enormes aplicações científicas e tecnológicas. $\mathrm{O}$ grau de confiança que os físicos têm na mecânica quântica é uma confiança que, eu diria, é quase ilimitada nesse sentido.

Contudo, nesta mesma disciplina, nesses 100 anos, temos presenciado um intenso debate, às vezes mais intenso, às vezes menos intenso, sobre os fundamentos e sobre as interpretações desta teoria física. Tomemos como referência 1927, a Conferência de Solvay de 1927. Ali, quando a mecânica quântica é apresentada formalmente, ela é elaborada e interpretada nos marcos da chamada interpretação da complementaridade. Ali, também se instaura a divisão ou a cisão ou a polêmica particularmente entre Einstein e Bohr e que durou a vida, a existência de Einstein, que vai falecer em 1955, ainda terçando armas com Bohr. E Bohr vai falecer em 1962, ainda preocupado em como, mesmo a posteriori, encontrar os melhores argumentos para defender a interpretação da mecânica quântica dos seus críticos.

Sobre isso que eu quero comentar nesta palestra. Mas, falar de controvérsias nas teorias científicas e da Física não é propriamente uma novidade, porque todas as grandes teorias científicas e todas as teorias da física foram elaboradas nos marcos de certas controvérsias que duraram mais ou menos. Você pega a mecânica newtoniana, ela não foi aceita de imediato. Ela teve enorme resistência dos cartesianos em particular e dos continentais em geral. E se pode dizer que foram precisos uns 40 ou 50 anos para que, finalmente, o mundo culto do que se chamava na época de Filosofia Natural, matematizada, tenha aderido à mecânica newtoniana.

Mesmo assim, aspectos da mecânica newtoniana ficaram como, para usar esta expressão, "esqueletos guardados no armário". Foi o caso, por exemplo, da equiva- 
lência entre massa inercial e massa gravitacional, ou do espaço e tempo absolutos. No século XIX, isso voltou à tona particularmente quando Ernest Mach fez um grande desafio à mecânica newtoniana. Então, controvérsias não são novidade. Com qualquer outra teoria, vamos encontrar controvérsias desse tipo. Vejamos o caso da relatividade especial. Ela aparece toda pronta nos artigos do Einstein de 1905, mas a aceitação da relatividade especial, em particular a aceitação do princípio da relatividade, foi mais ou menos demorada, variando de país para país. Na Alemanha, e graças a Max Planck, a aceitação foi imediata. Mas, se você olhar para a França, até meados dos anos 1940, a relatividade ainda não tinha chegado no ensino universitário. Então, por isso, a recepção da relatividade especial tem sido um tópico de investigação histórica. Com a relatividade geral, temos um pouco a mesma coisa. A aceitação foi mais rápida, mas os debates sobre as implicações físicas da teoria persistiram por décadas.

Então, falar de controvérsia não é o elemento novo interessante. Claro que a controvérsia da mecânica quântica tem algumas particularidades, é uma controvérsia sobre fundamentos e sobre as interpretações, mas uma particularidade importante é que é uma controvérsia que não está fechada, nós somos partícipes dessa controvérsia.

Quando eu estava na minha graduação, no meu mestrado, fiquei fascinado por esse tema. Eu, sendo professor do Instituto de Física, compreendi que estava imerso nesta controvérsia. Aliás, na minha trajetória profissional, um grande desafio, quando eu sistematizei a minha decisão de me envolver como a história da ciência, foi o de adquirir algum grau de distanciamento para permitir escrever a história, por exemplo, desse debate, dessa controvérsia. Não é a mesma coisa que você falar sobre a controvérsia sobre a recepção da relatividade especial, em que, em meados da década de 1940/1950, o assunto estava resolvido. A mecânica quântica, a interpretação de seus fundamentos, isso aí não está resolvido. Então, essa primeira particularidade é interessante.

Há uma segunda particularidade que é a seguinte: ela é uma das controvérsias, eu diria assim, mais fecundas que nós temos na história da física, na história da ciência. Fazendo uma comparação, aqui, um pouco grosseira, se você pegar a crítica do Ernst Mach ao conceito de espaço e tempo, ao conceito de inércia, presente na mecânica newtoniana, e se você força um pouco a mão, mas não muito, levando a sério a afirmação de Einstein de que ele foi muito influenciado pelas críticas de 
Mach, quer dizer, a mecânica deixou de ser a sacrossanta mecânica para ele pela influência intelectual do Mach, você pode dizer, também, que a crítica de Mach teve efeito fecundo na obra do Einstein.

No caso da mecânica quântica, nós temos um efeito semelhante, só que amplificado. Hoje, se você perguntar a qualquer físico qual é o efeito físico estritamente quântico mais importante, ele vai te dizer: o emaranhamento quântico. Se você vai para o pessoal que está mexendo com uma das fronteiras da pesquisa em física, tudo que envolve informação quântica (criptografia, computação quântica), eles vão te dizer o seguinte: é o emaranhamento. O problema é que o emaranhamento é um conceito físico, um fenômeno físico, do qual hoje nós temos convicção de que é um fenômeno físico, graças a esse debate sobre a interpretação da quântica. Ele foi fruto dessa controvérsia por caminhos um pouco complicados. E Einstein foi o primeiro a ver nitidamente o problema, embora tivesse pensado que isso era uma limitação da teoria, um sinal de incompletude da teoria quântica.

Posso citar um ou dois físicos importantes: Nicolaas Van Kampen, por exemplo, holandês, uma das vezes ele disse: "mas isso está na estrutura matemática, você pega o átomo de hélio, as funções ali já estão emaranhadas". Mas ninguém imaginava, entre 1927 e 1935, que aquele emaranhamento na descrição dos dois, aquele acoplamento do estado na descrição dos dois elétrons poderia valer quando você afastasse aqueles elétrons a distâncias macroscópicas. Tanto era assim, que Einstein não foi o único a desconfiar, Schrödinger desconfiou disso, inclusive, foi ele quem criou o termo "entangled" (emaranhamento). Outros desconfiaram disso. Wendell Furry, que foi um físico norte-americano, levantou a hipótese de que depois de uma certa distância, esse estado não fatorizável se separaria em dois estados independentes. Mas Einstein é quem viu nitidamente o fenômeno implícito no formalismo matemático da quântica e não aceitou, ele achou que isso era um defeito, uma evidência da incompletude da mecânica quântica, mas ele teve o mérito de ter visto isso naquele hoje famoso experimento de pensamento concebido por ele, Podolsky e Rosen, o EPR. Portanto, essa segunda particularidade, que é muito interessante da história de mecânica quântica, é que esse debate teve, e tem tido, um impacto imenso no desenvolvimento da própria mecânica quântica.

Feito esse comentário inicial, o que quero falar é que, como estamos, aqui neste encontro, interessados em história, filosofia e ensino de Física, escolhi três aspectos da controvérsia e quero comentá-los e fazer certas conjecturas sobre implicações 
para o ensino de Física. Ou seja, o que falo a seguir não é resultado de uma pesquisa sistemática sobre a implicação para o ensino de Física, quero fazer conjecturas. E quais são os três aspectos que eu vou selecionar? No primeiro deles, quero olhar muito rapidamente como é que os próprios físicos encararam essa controvérsia ao longo da história. Qual foi a atitude que prevaleceu entre os físicos?

No segundo aspecto, quero comentar sobre como é que os filósofos da ciência, que tinham interesse na filosofia da física, olharam para essa controvérsia? A mesma coisa, ao longo da história, como é que eles reagiram? E, no terceiro aspecto, o que quero olhar é para experimentos e fazer outra pergunta: o que é que esses experimentos, relacionados à controvérsia sobre a interpretação dos fundamentos da mecânica quântica, podem nos dizer sobre a controvérsia? E, do mesmo jeito, que conjectura posso tirar dessa ponderação para o ensino de Física? É esse, então, que é o meu desafio aqui hoje.

\section{O debate sobre a interpretação da quântica e a história da Física}

Comecemos pela atitude dos físicos. Quando comecei a trabalhar sobre a história dessa controvérsia, tive um primeiro desafio, que foi um desafio de escrever uma cronologia, uma periodização. É um pouco a mania de historiador, o historiador, se não tem os marcos periódicos, ele fica meio perdido. Eu fiz uma certa periodização, e cito isso porque a Andrea Guerra fez referência a Michael Matthews, que é um professor que já veio ao Brasil várias vezes, e o Michael Matthews ouviu eu falando desta periodização. Estávamos em um evento, em Viseu, Portugal, 2001, e, por iniciativa dele, ele disse assim: "Você não quer submeter esse texto à Science \& Education?".

$\mathrm{O}$ texto ainda era muito embrionário. Na verdade, o texto era quase uma versão do projeto que eu tinha apresentado na época para o CNPq, em 2001. Tenho, portanto, com a revista Science \& Education essa ligação, diria quase que afetiva. Esse artigo saiu em um número dedicado à mecânica quântica, aliás, o Michael Matthews era um editor que vivia pelo mundo de olho em apresentações, a captar artigos. Nesse número, também saiu um artigo da Ileana Greca em que sou coautor, ela foi orientada pelo Marco Antônio Moreira e trabalhou sobre o ensino da mecânica quântica no seu doutorado na Universidade Federal do Rio Grande do Sul. 
Nesta periodização, grosso modo, a primeira parte do debate foi aquela marcada pela participação dos fundadores da mecânica quântica. Um grande debate entre Einstein e Bohr, entre Schrödinger e Bohr, no qual as questões inicialmente envolviam o problema do determinismo e rapidamente evoluíram para o problema da completude: estamos diante de uma teoria completa ou diante de uma teoria provisória? Nesse período, o debate sobre os fundamentos da teoria quântica era um debate prestigiado, afinal de contas, era um debate em que estavam Einstein e Bohr, "trocando tiros" na revista Physical Review. Depois, temos uma fase que começa no final dos anos 1940 e início dos anos 1950 e que vai até os anos 1970/1980, que é uma fase intermediária, uma fase que caracterizo como aquela em que essa controvérsia passou a ser considerada pelos físicos uma perda de tempo, e é isso que eu quero ilustrar um pouco mais aqui.

Em algum momento mais tarde, essa controvérsia voltou a mudar, e aí a gente poderia discutir: mudou quando os experimentos do Alain Aspect foram publicados, em 1881-1982, ou mudou para valer mais no final dos anos 1980? Certamente, dos meados da década de 1990 em diante, ninguém tem dúvida que mudou, porque entrou um tema que absorveu parte dos fundamentos da mecânica quântica, que foi o tema da informação quântica. Certamente, nessa última etapa, que vivemos até hoje, não se pode falar que esse debate é um debate mal visto. Hoje, se você pega um grande físico brasileiro, ele vai falar sobre o emaranhamento quântico, vai lembrar do Einstein e da resposta de Bohr. Mas, naquele período intermediário, a atitude dos físicos foi uma atitude que, eu diria, muito negativa.

Então, essas são as questões que quero apresentar em grandes linhas. Mas, quero agora ilustrar essa atitude negativa, essa má vontade, daquela fase intermediária, com três ou quatro casos, para ilustrar essa má vontade reinante entre os físicos no que diz respeito aos debates sobre interpretação da mecânica quântica. Quando comecei a trabalhar com a história desse problema, por vezes, eu me fazia a seguinte pergunta: será que as declarações de Bell, de Aspect, não estão querendo valorizar a trajetória que levou os debates dos fundamentos da mecânica quântica a se tornarem o elemento central da área de informação quântica? Será que não tem assim, um pouco, essa história de você reconstruir a sua história para valorizar sua própria trajetória? Será que eles não estão criando uma espécie de um mito de origem? 
Fiquei muito contente quando, no trabalho usual de historiador, consultando fontes da época, cartas e publicações, comecei a encontrar evidências da época, portanto, não vistas em retrospectiva, que confirmavam essa má vontade, esse estigma. Então, cito aqui esse trabalho de 1966 que é publicado pelo John Bell, este grande físico, e Michael Nauenberg, que está vivo ainda e que sintetiza muito bem o que era a atitude de má vontade entre os físicos em relação aos fundamentos da mecânica quântica. Bell dizia: "nós enfatizamos não somente que a nossa visão [a visão deles era que a mecânica quântica era, no melhor dos casos, incompleta] é aquela de uma minoria, mas também que o interesse atual em tais questões é pequeno. O físico típico acha que essas questões dos fundamentos da mecânica quântica já foram respondidas há muito tempo e que ele entenderá completamente, basta que ele possa poupar 20 minutos para pensar sobre esses assuntos".

Da mesma época, tem uma carta, que eu encontrei no arquivo do Léon Rosenfeld, em Copenhague, que era muito ligado a Bohr, na qual ele escreve para o Bell, e essa carta é muito importante porque é do ano que o John Bell publica o seu teorema. O teorema que hoje permitiu-nos decidir no laboratório se, afinal de contas, o emaranhamento quântico era um fenômeno físico ou não. O Rosenfeld, então, no fogo dos acontecimentos, ele escreve para o Bell, expressa um grande respeito por Bell por este ser um físico da área de partículas e aceleradores, mas Rosenfeld diz essa pérola: "Eu não preciso dizer que eu considero sua caça de parâmetros escondidos um desperdício do seu talento e eu não sei também se você vai ficar alegre ou triste por aquilo". Ou seja, você pega um físico do porte do Rosenfeld, podemos dizer assim, o último dos grandes herdeiros da interpretação da complementaridade do Bohr, e ele achava essa busca do Bell, se afinal de contas era ou não possível complementar a mecânica quântica com teorias com variantes adicionais, ele achava isso desperdício de talento.

Sigamos: o livro do Messiah, cuja edição em francês é um pouco anterior, mas essa versão em inglês é de 1961, é um livro que aceita que tem uma controvérsia, mas ele qualifica esta controvérsia como sendo uma controvérsia filosófica. Portanto, não é assunto para físico, é para filósofo. Então, está lá no livro do Messiah: “a controversa sobre variáveis escondidas finalmente atinge um ponto onde ela não pode mais ser decidida por qualquer observação experimental adicional, por isso ela pertence daqui para frente à filosofia da ciência mais do que ao domínio da ciência física propriamente dita”. 
Dito de maneira muito mais polida do que disse Rosenfeld, mas o recado aqui é o seguinte: se você tiver um aluno que queira fazer um doutorado em fundamentos da mecânica quântica, nesse problema da completude da mecânica quântica, não deixe ele fazer isso, porque isso é o domínio de filosofia da ciência, manda ele fazer uma tese no departamento de Filosofia.

Trago uma outra evidência que é uma carta do Michael Hammerton de 1971. Como pano de fundo para esta carta, há todo um contexto que não vou aqui me estender, mas a revista Physics Today, em 1970, por certas circunstâncias, tomou a decisão de abrir um debate sobre as interpretações da mecânica quântica. Ela publicou um artigo de Bryce DeWitt, apresentando a diversidade de interpretações e defendendo a interpretação de muitos-mundos; e depois publicou vários artigos debatendo o artigo do DeWitt; e, ainda, depois, publicou uma série de cartas sobre o tema. Aqui, entra o Michael Hammerton, da área de biofísica médica. Ele diz algo que achei muito interessante sobre o artigo do DeWitt, que provocou esse debate intenso. Ele diz que este episódio exemplifica os modos sutis e altamente complexos pelos quais a opinião científica pode mudar e afirma: "Quando eu era um estudante de graduação de Física, 20 anos atrás, portanto, 1951, a linha de Copenhague era 'científica', qualquer coisa fora disso era sem significado, mumbo-jumbo [expressão típica em inglês para enrolação ou, na melhor das hipóteses, coisa errada]. Agora a coisa curiosa e que não consigo compreender é que não há nenhum grande desenvolvimento ou insight teórico novo, que possa ter demolido ou superado essa interpretação; apesar disso existe agora uma considerável insatisfação com essa interpretação e uma vontade de olhar outros pontos de vistas, por exemplo, variáveis escondidas como sendo pelo menos respeitadas". Então, essa carta evidencia exatamente essa transição, que, no meu argumento, é uma transição que começa ali exatamente 1970-1971, mas vai se consolidar efetivamente 10 anos depois, com os experimentos de Alain Aspect.

Agora, essa má vontade contra a pesquisa em interpretações e fundamentos trouxe efeitos negativos muito concretos para a Física. Vou ilustrar esses efeitos negativos com dois grandes físicos que tiveram suas carreiras científicas truncadas, porque se dedicaram à área de fundamentos e de interpretação da mecânica quântica.

O primeiro deles é John Clauser, um grande físico experimental, que concluiu tese em 1968/1969 na Universidade Colúmbia, com Patrick Thaddeus, sobre radiação cósmica de fundo, o que era um tópico altamente quente na época, como podem se 
lembrar do trabalho de Arno Penzias e Robert Wilson de 1964/1965, com a primeira detecção desta radiação. Clauser se encantou com o artigo do Bell e, junto com Abner Shimony e mais duas outras pessoas, escreveu um artigo que é chamado CHSH (acrônimo para os autores: Clauser, Horne, Shimony e Holt), e lidera um dos dois primeiros grupos que resolvem testar no laboratório se, afinal de contas, era o realismo local, defendido pelo Einstein, ou a mecânica quântica que estava correta. E ele conduz o experimento que é um marco na história da física, corroborando as predições da mecânica quântica, o experimento de Freedman e Clauser de 1972.

No que pese ter sido formado pela Universidade Columbia e ter feito esse experimento crucial, ter escrito esse artigo assinado pelos quatro que permite o teorema de Bell ser levado para os laboratórios e ter publicado outros trabalhos relevantes na época; no que pese tudo isso, Clauser nunca encontrou um emprego permanente nas universidades norte-americanas. Ele não morreu de fome, evidentemente, como grande físico experimental, ele recorreu sempre a uma estratégia que é típica dos Estados Unidos, da Europa também, em que você faz um projeto de pesquisa e você embute no projeto a remuneração do pesquisador.

Nas nossas pesquisas, encontramos muitas evidências da má vontade que existia à época contra o tipo de física que o John Clauser estava fazendo, e não são poucas evidências. Se pegarmos o livro que publiquei - Os dissidentes quânticos -, tem várias cartas, várias referências. Agora, essa carta é particularmente importante porque ela foi escrita pelo Abner Shimony, que era muito amigo do Clauser, para ele, em 1972, e o Shimony soube pelo seu amigo, físico francês, Bernard d'Espagnat, que este havia recebido uma consulta do chefe do departamento da Universidade da Califórnia, em São José.

Para entendermos melhor este episódio, cabe notar que esse negócio de concurso nas universidades americanas não tem o mesmo procedimento que nas universidades brasileiras. Funciona do seguinte modo: um departamento quer contratar alguém, o chefe do departamento manda uma, duas, três, quatro cartas a pessoas experientes no campo, perguntando a opinião destas pessoas sobre o candidato. Se essas pessoas forem muito favoráveis, o departamento chama o candidato para apresentar um seminário, e é assim que o departamento decide a contratação. Então, o que está aqui na forma de uma carta parece uma coisa, assim, inodora, uma carta, na verdade, é um processo seletivo em andamento. Então, ele, Shimony, disse assim para o Clauser: "eu encontrei o Bernard d'Espagnat na última semana [porque nessa 
época o Shimony estava na França] e o d'Espagnat recebeu uma carta do chefe do apartamento de São José perguntando se o que você [Clauser] está fazendo é física verdadeira". Ou seja, na altura de 1972, um chefe de departamento de uma grande universidade americana tinha dúvida se o tipo de física experimental que o Clauser estava fazendo, se era física, física verdadeira (real physics). O Shimony prossegue informando que d'Espagnat vai escrever uma forte carta respondendo à questão a favor de Clauser. Shimony conclui: "lamento que, a partir dessa evidência, a situação de seu emprego está ainda não resolvida”. E continuaria sem solução.

Pego o segundo caso, que é mais simples, Hugh Everett é um físico teórico, matemático, com seu doutorado em Princeton em 1957, orientado por John Archibald Wheeler. Efetivamente, ele fez toda uma carreira em Matemática, trabalhando para o sistema de defesa norte-americano, mas a tese dele é sobre os fundamentos da mecânica quântica, a tese é sobre o que a gente chama hoje: a interpretação dos estados relativos e que, mais tarde, o DeWitt vai chamar de interpretação de muitos mundos, expressão essa que o Hugh Everett nunca usou. O que foi a sorte do Hugh Everett foi também a tragédia dele: a sorte é que ele chega então em Princeton, uma universidade de ponta, o John Archibald Wheeler, que era um Bohriano, fica interessado por uma tese naquele tema e, então, "patrocina" a tese. Wheeler considerava a sabedoria de Bohr no patamar daquela de Platão, de Cristo e de Buda, para se ter uma ideia da elevada referência que ele tinha de Bohr.

Wheeler orienta a tese, dá o nome como orientador, mas ela é feita integralmente pelo Everett, e é uma interpretação alternativa na qual você elimina o colapso da função de onda, você elimina o postulado do Von Neumann da redução do operador, o que fisicamente se chama de colapso do pacote de onda. Essa interpretação, que depois vai ser influente, vai ser influente em computação quântica, hoje tem muita gente que trabalha com ela, tem gente que critica ela, enfim, esta interpretação alternativa sai como uma tese de Princeton, mas o azar é que Wheeler fica encantado com a tese, mas diz para o Everett duas coisas.

Primeiro, Everett teria que convencer Bohr de que a tese estava correta, que estava adequada, e Wheeler queria que a tese fosse publicada nos anais da academia dinamarquesa de ciência, para que, ao ser publicada na Dinamarca, a tese tivesse o nihil obstat do Papa, no caso, Bohr. Bohr não aceitou a tese do Everett, nem ele, nem Rosenfeld, e criticaram a tese do Everett fortemente. Wheeler então 
enquadrou Everett, e por isso que hoje quem conhece a história da tese de Everett tem que lidar com a chamada tese longa e a tese curta.

A tese longa é a tese inicial escrita por Everett e levada a Copenhague pelo próprio Wheeler, para receber a benção de Bohr, o que não aconteceu. Já a tese curta é o seguinte: Wheeler pediu a Everett para cortar mais de $50 \%$ da tese e qualquer referência ao problema de interpretação da quântica, para que ela ficasse assim, se não palatável, pelo menos não tão incômoda à visão sustentada por Bohr, da interpretação da complementaridade, por vezes chamada de interpretação de Copenhague. Todas as referências críticas à Interpretação da complementaridade foram tiradas na versão da tese curta, e ela foi assim aprovada em Princeton. O resultado é que Everett ficou chateado com aquilo e, como era um matemático brilhante, começou a ser atraído por contratos na defesa americana. Aí, mandou a física passear e nunca voltou a escrever um artigo em física.

Aqui, trago uma carta do Rosenfield, de início dos anos 1970, para Frederik Belinfante, como a tese foi publicada em 1957, portanto a carta é de praticamente 15 anos depois. Rosenfield escreve para Belinfante, e a carta expressa o modo como Everett foi encarado em Copenhague. "No que diz respeito a Everett nem eu, nem mesmo Niels Bohr, podíamos ter qualquer paciência com ele quando ele nos visitou em Copenhague mais do que 12 anos atrás [ele visitou em 1959] de modo a vender as suas ideias desesesperançosamente erradas sobre as quais ele tinha sido encorajado - de maneira pouco sábia por Wheeler - a desenvolver". Então, ele acrescenta: "ele [Everett] era indescritivelmente estúpido e não podia entender as mais simples coisas em mecânica quântica".

Conclusão que posso tirar desse episódio: os físicos nem sempre ficaram bem na fita no que diz respeito aos fundamentos da mecânica quântica. É muito bonito hoje um físico que vai falar sobre emaranhamento, fala o EPR, traz a foto do Einstein, diz que ele está errado e que Bohr está certo, mas esconde, joga para debaixo do tapete todo esse jogo sujo praticado na Física nos anos 1950-1960-1970. É uma época, portanto, em que a Física teve pouca tolerância. Acho que esse episódio todo tem uma lição, primeiro, para a Física. Ou seja, a Física, como todas as comunidades disciplinares, por vezes, pode ser muito pouco tolerante às ideias novas, ou excessivamente crítica das ideias novas.

Acredito que isso também pode ter uma implicação que vou simplesmente conjecturar: será que o ensino de mecânica quântica que hoje é esse desafio educacional 
absolutamente crucial, porque a gente precisa generalizar o ensino de mecânica quântica, mas será que esse ensino de mecânica quântica não seria beneficiado se, ao invés de os professores de Física esconderem esse debate, eles explicitassem que esse debate existiu, que esse debate continua existindo? Essa é uma questão para uma decisão no âmbito da cultura do ensino de física. E é uma questão importante para o ensino de mecânica quântica, que é um enorme desafio, está certo, porque muitas vezes o que é que acontece? Você ensina mecânica quântica normal, e, no semestre seguinte, chega aquele aluno mais esperto e diz: "professor, e aquela crítica que o Einstein tinha da mecânica quântica"? Ou seja, o aluno pode achar que foi interditado de conhecer aquela interessante história, literalmente porque $o$ professor escondeu do aluno as críticas que o Einstein tinha da mecânica quântica. Então, é essa questão que o ensino de física deve examinar.

Acho que isso também valeria para outras temáticas. É preciso um certo equilíbrio entre defesa das ideias e teorias bem estabelecidas com flexibilidade e tolerância para aceitação de desafios. É esse equilíbrio que a ciência tem que buscar sempre para se fortalecer. Certamente, esse equilíbrio foi mal resolvido no caso da Física e no caso dos fundamentos da mecânica quântica nos anos 1950/1960 e 1970, e ele não devia ser escondido do ensino de Física.

\section{Filósofos da ciência}

Daqui para frente, eu mudo um pouco de assunto, não falo mais dos físicos e passo mais rápido. Eu quero falar dos filósofos da ciência. Aqui, a situação é muito complicada, porque hoje tem uma comunidade importante de filosofia da mecânica quântica que está alojada nos departamentos de filosofia, que trabalha sobre fundamentos da mecânica quântica. Aliás, há dois meses, eu fui à Universidade Federal de Santa Catarina, ao Departamento de Filosofia, e lá, sob a liderança do Décio Krause, eles organizaram um importante evento dedicado a fundamentos da mecânica quântica. Eu fui e fiz uma palestra, então, você olhando assim pode achar o seguinte: é normal que os filósofos da ciência tenham sempre se interessado e apoiado o debate sobre os fundamentos da mecânica quântica. Mais ou menos, veja, se você olhar para o Popper, que na Federal do Rio Grande do Sul ele tem um grande amigo, o Fernando Lang, que é popperiano de carteirinha; aliás, a nossa amizade começou quando ele me mandou a dissertação de mestrado, ou a tese de doutorado 
dele, sobre Popper e a mecânica quântica, isso lá nos idos de 1990-1991-1992. O Popper se engajou nesses debates, e o terceiro volume do postscript do "Lógica da descoberta científica" é dedicado ao que ele chama de "O cisma da Física".

Um outro grande filósofo, o Feyerabend, também se envolveu muito fortemente na mecânica quântica. Aliás, eu antecipo que, nesse livro, o handbook da Oxford, vai ter um capítulo exatamente sobre as visões do Feyerabend sobre a mecânica quântica, mas nem todos os grandes filósofos da ciência tiveram atitude desse tipo. É mais ou menos bem sabido que não foi a atitude do Thomas Kuhn, cuja visão era a seguinte: teve uma revolução científica? Teve, ela acabou em 1927, quando a mecânica quântica foi formulada, dali para frente, era ciência normal. Reabrir esse debate sobre interpretações era confundir, na visão do Thomas Kuhn, ciência normal com período de revolução científica, e você sabe que, se misturar período de revolução científica com os períodos de ciência normal, o edifício do "Estrutura das Revoluções Científicas”, esse best-seller, essa grande contribuição do Tomas Kuhn para a filosofia da ciência, desmorona.

Vejamos como essa visão do Kuhn foi criticada. Mara Beller, em seu livro Quantum Dialogue, fez uma crítica frontal. Ela analisa os debates no início da mecânica quântica e argumenta que o diálogo aberto foi fechado a uma certa altura, próximo a 1927-1928, com o estabelecimento da interpretação da complementaridade e a forte adesão dos pais fundadores da mecânica quântica a ela. No fim do livro, Beller sustenta que a noção de paradigma de Thomas Kuhn é uma tradução, para a filosofia da ciência, da monocracia da interpretação de Copenhague, da interpretação da complementaridade.

Mais recentemente, escrevendo uma biografia sobre David Bohm, eu terminei encontrando algo que estava publicado, mas em debates registrados em um desses proceedings (atas de conferências). Foi uma descoberta que, para mim, foi absolutamente fantástica. Esses debates estão nos proceedings de uma conferência de 1969, nos Estados Unidos, organizada pelo Frederick Suppe, na qual Kuhn estava presente, Bohm estava presente, mas não presencialmente, pois a contribuição dele foi lida por um ex-aluno, o Jeffrey Bub. A intervenção de Kuhn tem essa preciosidade, olhem o que é que ele diz: "É a minha impressão que uma das maiores dificuldades enfrentadas pelas pessoas que estão dedicadas a revisar a interpretação de Bohr, é que nenhum dos problemas que emergem para essas pessoas faz qualquer contato 
com os problemas técnicos que a Física tem enfrentado nos últimos anos, nos anos recentes. E isto tem criado uma profunda crise para a profissão".

Ou seja, Kuhn está nos dizendo que os debates sobre a interpretação, sobre interpretações, sobre fundamentos da mecânica quântica, criaram uma crise na profissão. Você troca Kuhn por Rosenfeld e não tem diferença no conteúdo e no estilo das atitudes deles. A reação do Jeffrey Bub, eu achei fenomenal, porque ele reagiu bem, ele disse assim: "Algo sobre o que o professor Kuhn acabou de dizer realmente me incomodou”. E tem uma curiosidade, porque o Bub fez a tese de doutorado dele em 1964, sob a orientação de David Bohm, sobre introdução de variáveis escondidas na mecânica quântica. Então, Bub se sentiu até, pessoalmente, criticado; era quase uma crítica ad hominem. Mas não é por aí que o Bub vai se defender, vejamos como ele se defende: "Alguma coisa sobre o que o professor Kuhn acabou de dizer realmente me incomodou, ele sugere que devamos nos preocupar apenas com o que a maioria dos físicos está preocupada hoje".

Bub prossegue, em uma frase muito expressiva: "Qual o significado para a filosofia da ciência é o fato de que hoje, ou nos últimos 30 anos, os físicos, em sua maioria, têm estado preocupados com certos tipos particulares de problemas e que outros certos problemas tenham sido abandonados como irrelevantes. Nomeadamente o problema da interpretação da teoria quântica”. Então Bub se pergunta: “Qual o significado disso para a filosofia da ciência?”. Para a Física, ele não está discutindo, mas e para a filosofia da ciência? Então, Bub conclui: "Eu penso que esse é realmente um modo muito peculiar de olhar para a história da física ou para o modo pelo qual a física é desenvolvida, e então tomar aquilo que a maioria dos físicos está fazendo como uma espécie de padrão sobre o qual basear uma metodologia no sentido prescritivo". É como se Bub estivesse dizendo: Thomas Kuhn está reificando a ciência, transformando a ciência numa metodologia, atribuindo à prática da ciência, num dado momento, um valor prescritivo. Esta é a mesma crítica que, mais tarde e em outros termos, vai ser feita pela Mara Beller.

Agora, eu passo rápido para mostrar que, desde então, outros filósofos também têm batido na mesma tecla. Cito, por exemplo, o trabalho de Machamer de 2000, que é um estudo sobre controvérsias, mas é um estudo no qual as controvérsias sobre a mecânica quântica não tiveram muito papel nesse volume. Machamer sugere que Einstein, que tinha desafiado a viabilidade lógica e filosófica da interpretação ortodoxa da mecânica quântica: "Finalmente, implicitamente reconheceu que em 
termos de argumento ele foi derrotado". Então, ele cita, em apoio a esta suposta derrota, uma carta do Einstein para Bohr em 1947. Trata-se de uma má leitura da carta de Einstein e do seu contexto. Einstein escreve para Bohr: "Eu não posso, contudo, basear essa convicção da crítica na mecânica quântica sobre razões lógicas, mas posso somente produzir meu pequeno dedo como testemunha".

Contudo, um ano e meio depois, Einstein vai escrever, naquela coleção sobre os cientistas, um volume com artigos a ele dedicados e vai reiterar todos os seus pontos de vista da mecânica quântica. Isto está no artigo final - "Resposta aos críticos" daquele volume. Einstein ainda vai publicar um outro artigo em 1953, reafirmando suas visões sobre a mecânica quântica. Então, Einstein não se considerou derrotado, ele era a minoria, mas ele foi até o fim defendendo seu ponto de vista.

A história do envolvimento dos filósofos da ciência com o debate sobre a interpretação da mecânica quântica traz uma possível implicação para o ensino. É muito importante que os nossos estudantes conheçam Popper, Kuhn, Lakatos e todos os outros, mas é muito importante também que eles conheçam criticamente esses filósofos da ciência. Não podemos santificar nenhum dos filósofos da ciência, porque eles foram parte da cultura científica e filosófica do século XX. Isso torna mais complicada a introdução da filosofia da ciência no ensino de ciência? Torna, mas não tem escapatória. Ciência e filosofia são produzidas imersas em dados contextos culturais.

\section{Experimentos em fundamentos da Física Quântica}

Passo agora para a última parte da minha apresentação, falarei sobre experimentos. $\mathrm{O}$ assunto é vasto e justificaria uma outra apresentação, mas eu quero falar do significado dos experimentos relacionados a fundamentos e interpretações da Física Quântica; do significado partilhado pela grande maioria dos físicos. Estes experimentos, feitos a partir da década de 1970, principalmente a partir do trabalho do Freedman, do Clauser e de toda a série de experimentos que até hoje estão sendo desenvolvidos, eles podem ser condensados na seguinte apreciação: o desenvolvimento da técnica, nos últimos anos, permitiu que experimentos de pensamentos sejam transformados em experimentos reais, experimentos de laboratório, então, esta que é a grande novidade. Esta foi, por exemplo, a abordagem da aula inaugural de Serge Haroche no Collège de France. 
Mas, a essa grande novidade, eu quero agregar dois comentários finais. O primeiro é que esses experimentos permitiram a manipulação de sistemas quânticos individuais, fóton um a um, elétron um a um, cavidades de ressonância, técnicas que permitiram experimentos de dupla fenda com elétrons, um a um, com fótons um a um, experimentos de escolha retardada, todos os experimentos envolvendo o teorema de Bell e as desigualdades, experimentos que permitiram levar o gato de Schrödinger para o laboratório, este último experimento - tipo gato de Schrödinger foi um trabalho do Serge Haroche que acabei de citar. Mas, a motivação técnica disto não derivou dos fundamentos da mecânica quântica, então esse é o primeiro alerta.

Foi uma inovação técnica, o elemento isoladamente mais importante foi o laser, o segundo talvez mais importante foi a generalização do uso da informática nos experimentos, particularmente em ótica. Então, isso, para mim, encerra uma certa lição sobre como é que a física se desenvolve, que eu diria assim: aqui eu já abordo uma possível explicação para o ensino, ao introduzirmos filosofia da ciência no ensino, a gente deve ir "devagar com o andor", na ideia dos pós-positivistas que criticam a ideia de que o experimento tem primazia, observações têm primazia. A crítica dos pós-positivistas tem razão, não estou tirando a razão deles. Os experimentos são carregados de teoria, você olha para um experimento já com uma dada lente teórica.

Mas, o "devagar com o andor" é que, no desenvolvimento da Física, não é verdade que a experimentação esteja sempre subordinada ao desenvolvimento das teorias, e não é verdade que o desenvolvimento da técnica esteja sempre subordinado à experimentação, eles têm dinâmicas próprias, e quando você olha para os últimos 50/60 anos, foi isso que aconteceu, ou seja, foi a área de fundamentos que se apropriou desses desenvolvimentos técnicos e fez esses experimentos fenomenais.

Acho isso muito importante, porque, em geral, nós temos um problema com a área da física experimental no Brasil. Ela tem sido menos subdesenvolvida, se comparada com a física teórica, e muitas vezes a explicação para isso é o subfinanciamento da Física, particularmente nos anos de 1980-1990. Mas, há uma razão mais de fundo, que não podemos esquecer, de que vivemos numa sociedade que era baseada na escravidão até um século atrás, portanto, uma sociedade em que o trabalho experimental, e não tem trabalho experimental que não seja manual, sempre foi encarado com um pouco de desprezo. Poderia ilustrar isso com casos aqui do meu instituto, para não falar da casa dos outros. O que eu quero dizer é que seria muito 
saudável para a Física brasileira se tivéssemos uma atitude de mais consideração diante do físico experimental e do físico instrumentista.

Já vi muita gente dizer, diante de um físico, que é um bom instrumentista: “ah, ele é um engenheiro". Então, é esse que é o “devagar com o andor" que estou defendendo. Ou seja, todo esse desenvolvimento técnico, esses experimentos, por vezes, a motivação para o desenvolvimento técnico não deriva da necessidade da teoria. É como aquela história dos alpinistas. Se você pergunta por que mesmo que tem que escalar aquela montanha? A resposta será: "É porque ela está lá”. Então, por que que foi preciso correr atrás do laser? Ninguém tinha toda clareza de aonde o laser ia levar, no caso do laser, tinha algumas pistas, mas ele estava lá. Era uma possibilidade teórica, tinha que correr atrás, ou seja, tem uma dinâmica própria que não é subordinada à teoria, era isso que eu queria dizer.

Agora, temos o último aspecto que eu quero chamar a atenção. A lista de experimentos é uma lista fenomenal. Quero só mostrar, aqui, o último desses experimentos, com resultados publicados no ano passado. É um experimento que envolve fundamentos da mecânica quântica feito pelos chineses, liderados por Jian-Wei Pan. Ele foi um aluno do Anton Zeilinger em Viena na altura do ano 2000. Vinte anos depois, os chineses estão na liderança, digamos assim, de uma área que é fundamental para a Física básica e fundamental para as comunicações quânticas, que é manter o emaranhamento entre fótons, espacialmente separados, separados de distâncias entre satélite e base na terra da ordem de mil quilômetros. Tem um satélite que foi lançado em 2016, e esse satélite tem sido parte dos experimentos envolvendo emaranhamento quântico e criptografia quântica em desenvolvimento na China.

Por que isso é particularmente importante? Isso é particularmente importante porque, se os novos métodos de criptografia quântica vão revolucionar a sociedade, eles têm que funcionar na escala dos satélites. Hoje, eles funcionam muito bem na escala de distâncias entre dois pontos conectados por fibra ótica. Então, por exemplo, da Suíça, o grupo liderado por Nicolas Gisin tem sido capaz de ligar dois bancos suíços que estão separados por 100, $200 \mathrm{~km}$. Na China, os bancos entre Pequim e Xangai estão também conectados por fibra ótica. Mas, você não vai conectar a Ásia aos Estados Unidos, se não for pelo satélite. Então, portanto, experimentos com emaranhamento envolvendo satélites são impressionantes.

Faço agora meu último comentário e encerro com isso. Esses experimentos, particularmente os experimentos sobre emaranhamento quântico, têm trazido, 
diria assim, duas lições. Uma que a física incorporou bem. A outra, às vezes, digo o seguinte: lembra daquele filme do $\mathrm{Al}$ Gore, vice-presidente dos Estados Unidos, que escreveu o livro, que depois virou filme, sobre o aquecimento global, Uma verdade inconveniente? Então, a segunda parte da minha conclusão é uma verdade inconveniente para a Física, e precisamos saber se queremos enfrentar essa verdade ou não.

Sei que estou exagerando um pouco, mas é para tornar mais atrativa a conclusão da minha apresentação. Então, a primeira parte da conclusão dos experimentos é a seguinte. Hoje, pode-se dizer que todas as quebras do Realismo local, implícitas no emaranhamento da mecânica quântica, são tão desconcertantes às nossas intuições, às intuições do Einstein, que os físicos foram motivados, por décadas, a fazer experimentos mais sofisticados, fechando o que a gente chama de loophole, as escapatórias que poderiam explicar algum efeito não conhecido que explicasse aquelas correlações.

O último desses experimentos é fenomenal. É o experimento que foi conduzido pelo David Kaiser, que é um dublê de historiador da física e físico, e pelo Anton Zeilinger. O que é que eles fizeram? Um experimento usual com pares de fóton, correlacionados, que são medidos, contados, de acordo com suas polarizações. Mas, eles buscaram alterar a orientação dos polarizadores de um lado e do outro, em tempos menores do que o tempo que a luz gastaria para ir de um lado para o outro. Só que eles resolveram fazer isso usando uma técnica para gerar números aleatórios para definir a escolha das orientações dos polarizadores. E, ao invés de recorrer ao que se tem atualmente de gerador de números aleatórios, eles usaram outra técnica. Aliás, no passado, séries de números aleatórios estavam em livros grandes que ficavam na biblioteca da Física. O que é que eles fizeram? Eles captaram luz de quasares distantes de um lado e do outro. Dois quasares distantes, claro. Logo, luz vinda de duas fontes independentes, e usaram essa luz do quasar para, conforme a luz chegava, era uma dada orientação ou outra do polarizador que era ativada. $\mathrm{E}$ do outro lado a mesma coisa, de tal maneira, portanto, que, se existe algum efeito que explique esse emaranhamento quântico por uma correlação pré-existente, essa correlação vem desde o início do universo. Então, ou seja, temos, portanto, hoje boas razões para confiar que esse emaranhamento quântico é um fenômeno físico.

Vou agora para a segunda parte da conclusão, com a qual eu encerro. O emaranhamento quântico, então, descarta o chamado realismo local. A gente não sabe hoje se ele descarta o realismo, se descarta a localidade ou se descarta os dois. Não 
temos experimentos que permitam ir para um lado ou para o outro. Mas, o realismo local certamente está afastado. Agora, curiosamente, nem Einstein tinha uma interpretação alternativa que fosse realista local. A gente pode dizer que os experimentos descartaram uma certa classe de teorias (essa classe não estava preenchida ainda). Essa classe de teorias tinha o pressuposto do realismo local, o que é um bom pressuposto, em concordância com as boas intuições da física. Contudo, todas as interpretações alternativas existentes, a do David Bohm, a do Hugh Everett, por exemplo, todas elas trazem embutidas a não localidade da mecânica quântica. Portanto, até agora, esta que é a conclusão, nenhum experimento permitiu descartar uma das interpretações alternativas da mecânica quântica.

A pergunta que fica é a seguinte: será que é razoável imaginarmos que, no futuro imediato, vamos ter experimentos que permitam discernir uma interpretação da outra? Alguns físicos acham que sim. Basil Hiley, na Universidade de Londres, está montando um experimento para isto. Tem um outro, o Angelo Bassi, italiano, que está desenvolvendo um experimento para testar as ideias de Ghirardi, Rimini e Weber, de localização espontânea. Nos próximos anos, teremos estes resultados.

Mas, gosto de olhar para outra possibilidade. Qual é a outra possibilidade? É uma possibilidade que tem ressonância com uma tese da filosofia da ciência, que é a tese da subdeterminação das teorias pelos dados empíricos, que é chamada a tese de Duhem-Quine, que está meio fora de moda na filosofia da ciência. Vejamos: o aspecto lógico está de pé, mas essa teoria, essa tese, hoje, é suspeita de ter insuflado o relativismo na filosofia da ciência.

Lembro que, há 10 anos atrás, apresentei um trabalho, que falei sobre isso num congresso de filósofos. Mesmo os amigos, quase que vieram para cima: você está querendo jogar água no moinho do relativismo? Mas, se olharmos para o caso da mecânica quântica, será que não é uma situação desse tipo? Que os experimentos não serão capazes de discernir uma interpretação da outra? E, de maneira ainda mais audaz, aqui, a última conjectura mais forte. Quando olhamos para mecânica clássica, falamos de formalismo. Quando falamos da mecânica newtoniana, da lagrangeana, da mecânica de Hamilton-Jacobi, não falamos de teorias rivais, nem de intepretações rivais. Falamos, com naturalidade, que tal formalismo possa ser mais adequado a certas circunstâncias do que a outras. Será que o futuro da Física não vai nos reservar essa surpresa? A de termos, no futuro, daqui a 30 ou 50 anos, que conviver com as interpretações variáveis escondidas, estados relativos e colapso 
espontâneo, e outras tantas? Convivermos com distintas interpretações da mecânica quântica, portanto, compatíveis entre si de pleno direito, mas que são melhor aplicadas a certas situações do que a outras?

As implicações dessa conclusão final para o ensino são mais complicadas. Porque sei que um ponto importante é frisar a natureza empírica experimental da Física, mas essa natureza empírica precisa ser apresentada de maneira crítica, e não de maneira ingênua. Com isso, então, encerro a minha apresentação.

\section{The centenary debate on the interpretation and foundations of Quantum Physics}

\section{Abstract}

We analyze features from the history of quantum mechanics, in particular from the debate over the foundations and interpretations of this scientific theory. This analysis may be useful in the context of the Quantum Century project, which is being developed to reach its apex in 2025. Taking into consideration the quantum controversy, that is, the controversy over the foundations and interpretations of quantum mechanics, we discuss the three following features: physicists' attitudes towards the research on the foundations of this theory, philosophers of science's approach to that controversy and the role of experiments in the resolution of this controversy. Lessons from this analysis may be useful in the teaching of quantum mechanics, particularly in the students' early stage of contact with this scientific theory.

Keywords: history of Quantum Mechanics; complementarity; quantum dissidents.

\section{Nota}

1 Transcrição, revisada pelo autor, de palestra no I Encontro sobre História e Filosofia no Ensino de Física -26 de maio de 2021.

\section{Referências}

FREIRE JUNIOR, Olival. The Quantum Dissidents: Rebuilding the Foundations of Quantum Mechanics 1950-1990. Springer, 2015.

FREIRE JUNIOR, Olival. David Bohm: a life dedicated to understanding the Quantum World. Springer, 2019.

FREIRE JUNIOR, Olival. Making sense of the century-old scientific controversy over the quanta. In: FREIRE JUNIOR, Olival (ed.). The Oxford Handbook of the History of Quantum Interpretations. Oxford: Oxford University Press, 2022. 